\title{
Cirrhotic cardiomyopathy: Does it contribute to chronic fatigue and decreased health-related quality of life in cirrhosis?
}

\author{
Nigel Girgrah MD FRCPC ${ }^{1}$, Graham Reid PhD C Psych ${ }^{2}$, Shona MacKenzie BScN RN (EC) ${ }^{1}$, \\ Florence Wong MBBS MD FRACP FRCPC ${ }^{1}$
}

N Girgrah, G Reid, S MacKenzie, F Wong. Cirrhotic cardiomyopathy: Does it contribute to chronic fatigue and decreased health-related quality of life in cirrhosis? Can J Gastroenterol 2003;17(9):545-551.

Diminished health-related quality of life (HRQoL) and fatigue have been reported in patients with cirrhosis. The presence of cirrhotic cardiomyopathy and the attendant poor cardiac response to physical stress may affect HRQoL and contribute to fatigue in these patients. AIMS: To evaluate the contribution of cirrhotic cardiomyopathy to HRQoL and fatigue in ambulatory cirrhotic patients.

METHODS: Thirty ambulatory cirrhotic patients (14 preascitic, Child-Pugh score $5.6 \pm 0.3 ; 16$ ascitic, Child-Pugh score 9.1 \pm 0.5 ) underwent cardiopulmonary exercise testing and assessment of HRQoL, fatigue and depressive symptomatology. HRQoL and fatigue scores were correlated with liver disease severity, depressive symptomatology and parameters of cardiac function and exercise physiology.

RESULTS: Subscales of all HRQoL measuring the effect of disease on the ability to perform physical, social and emotional roles were significantly impaired when compared with controls $(P<0.001)$. The impact of fatigue, as assessed by the Fatigue Assessment Inventory, was greater in cirrhotics (4.46 versus 2.53 in healthy age-matched controls, $\mathrm{P}<0.01)$. Diminished HRQoL, impact of fatigue and vitality were related to depressive symptoms rather than to cardiac structural and functional abnormalities, which were present in cirrhotic patients. Poorer physical quality of life scores correlated with diminished mental health.

CONCLUSIONS: Depression, rather than the presence of cirrhotic cardiomyopathy, may have contributed to the diminished HRQoL and vitality in patients with cirrhosis with or without ascites.

Key Words: Cardiomyopathy; Cirrhosis; Fatigue; Health-related quality of life

$\mathrm{C}$ irrhosis is a major cause of morbidity and mortality worldwide (1). While liver transplantation has a proven benefit on survival for patients with end-stage liver disease (2), the survival benefit of other interventions, such as the insertion of a transjugular portosystemic stent shunt and antiviral therapy, is less clear. Therefore, parameters such as quality of life, mental and physical function, and specific complaints of fatigue have become important in the assessments of baseline function as well as in the response to an intervention in patients with cirrhosis.

Our clinical experience suggests that we would expect worsening symptoms and functional limitations with progression of
La cardiomyopathie cirrhotique contribue-t-elle à la fatigue chronique et à une réduction de la qualité de vie liée à la santé dans le cas de cirrhose?

Une réduction de la qualité de vie liée à la santé et une fatigue ont été observées chez des patients souffrant de cirrhose. La présence d'une cardiomyopathie cirrhotique et une mauvaise réponse cardiaque concomitante au stress physique peuvent avoir une incidence sur la qualité de vie liée à la santé et contribuer à la fatigue chez ces patients.

OBJECTIFS : Évaluer la contribution de la cardiomyopathie cirrhotique sur la qualité de vie liée à la santé et sur la fatigue chez les patients cirrhotiques ambulatoires.

MÉTHODES : Trente patients cirrhotiques ambulatoires (14 préascitiques, classification de Child-Pugh 5,6 $\pm 0,3 ; 16$ ascitiques, classification de Child-Pugh 9,1 $\pm 0,5$ ) ont subi des épreuves et une évaluation d'effort cardio-respiratoire de leur qualité de vie liée à la santé, de leur fatigue et de leur symptomatologie dépressive. Les scores de qualité de vie liée à la santé et de fatigue furent mis en corrélation avec la sévérité de la maladie du foie, la symptomatologie dépressive et les paramètres de la fonction cardiaque et de la physiologie de l'exercice.

RÉSULTATS : Les sous-échelles de toute la qualité de vie liée à la santé mesurant les conséquences de la maladie sur la capacité d'accomplir des rôles physique, social et émotif furent considérablement détériorées comparativement aux témoins $(\mathrm{P}<0,001)$. Les incidences de fatigue, telles qu'évaluées par l'échelle Fatigue Assessment Inventory, étaient plus élevées chez les patients cirrhotiques (4,46 contre 2,53 chez des témoins en santé du même âge, $\mathrm{P}<0,01)$. Une qualité de vie liée à la santé réduite, des incidences sur la fatigue et la vitalité étaient reliés à des symptômes de dépression plutôt qu'à des anomalies structurales et fonctionnelles du cœur qui étaient présentes chez les patients cirrhotiques. Les scores plus mauvais de qualité de vie physique correspondaient à une santé mentale amoindrie. CONCLUSIONS : La dépression, plutôt que la présence de cardiomyopathie cirrhotique, aurait pu contribuer à l'amoindrissement de la qualité de vie liée à la santé et de la vitalité chez les patients atteints de cirrhose avec ou sans ascite.

liver disease. Complications of liver cirrhosis (portosystemic encephalopathy, ascites, hernias and recurrent variceal hemorrhage) would further impact negatively on the patient's sense of well-being. Fatigue has been shown to be present in patients with various etiologies of chronic liver disease with or without cirrhosis, particularly chronic hepatitis $\mathrm{C}(3,4)$ and primary biliary cirrhosis $(5,6)$. A specific mechanism explaining the symptom of fatigue has not been defined.

Cirrhotic cardiomyopathy, a complication of cirrhosis, manifests with increased left ventricular mass and diastolic and systolic dysfunction (7), leading to reduced oxygen consump-

${ }^{1}$ Department of Medicine, Toronto General Hospital, University Health Network, University of Toronto, Toronto; and ${ }^{2}$ Departments of

Psychology and Family Medicine, University of Western Ontario, London, Ontario

Correspondence: Dr Florence Wong, 9EN/220, Toronto General Hospital, 200 Elizabeth Street, Toronto, Ontario M5G 2 C4.

Telephone 416-340 3834, fax 416-340 5019, e-mail florence.wong@utoronto.ca

Received for publication January 27, 2003. Accepted July 10, 2003 
tion and impaired cardiac response to physical stress (8). Cardiac systolic dysfunction in the setting of dilated or ischemic cardiomyopathy has been shown to correlate with the patient's functional capacity (9). However, whether this impacts on the quality of life of these patients is unclear. We postulate that the presence of cirrhotic cardiomyopathy, independent of the severity of the underlying liver cirrhosis, may also affect the functional capacity of these patients, with consequent reduction in health-related quality of life (HRQoL), or the ability of the patients to perform physical, social and emotional roles as a result of the disease, as well as contributing to the presence of fatigue in these patients. Therefore, the aims of the present study in patients with cirrhosis were to describe HRQoL and fatigue in a group of ambulatory cirrhotic patients; to assess the relationship between HRQoL and liver disease severity; to determine the contribution of cirrhotic cardiomyopathy to fatigue and changes in HRQoL; and to determine whether other factors such as depression contribute to fatigue and change in HRQOL in these patients.

\section{Patients}

\section{METHODS}

Thirty ambulatory, biopsy-proven cirrhotic patients (28 males, two females) with a mean age of $53 \pm 3$ years were recruited from the liver clinics of The Toronto General Hospital between July 1998 and December 1999. Informed consent to participate in the study was obtained. Fourteen patients (Pugh score 5.6 \pm 0.3 ; age $51.6 \pm 2.3$ years) had no history of ascites or diuretic use. Absence of ascites was confirmed by ultrasound before enrollment. These patients were therefore termed preascitic cirrhotic patients. The remaining 16 patients (Pugh score $9.1 \pm 0.5$; age $56.8 \pm 2.4$ years) had obvious ascites clinically and this was confirmed by ultrasound. Etiology of the cirrhosis in these patients included alcohol (18 patients); hepatitis C (nine patients); autoimmune hepatitis (one patient); hepatitis B (one patient); and drug-induced cirrhosis (one patient). All were ambulatory patients defined as being self-caring at home and being able to walk more than 1 to $2 \mathrm{~km}$ regularly.

Obesity, cachexia and anemia can all contribute to fatigue and reduced quality of life. Therefore, patients whose body mass index (BMI) exceeded 2 SD of normal (greater than $27.8 \mathrm{~kg} / \mathrm{m}^{2}$ for men, greater than $27.3 \mathrm{~kg} / \mathrm{m}^{2}$ for women) were excluded. Likewise, patients who were cachetic because of their liver disease (whose BMI was below 2 SD of normal) or who had anemia were excluded. A hematocrit of greater than $30 \%$ was required for enrollment. Patients were stable and free from gastrointestinal bleeding within the previous three months. Patients with other chronic systemic illnesses that could potentially contribute to a decreased HRQoL or fatigue were also excluded. Patients with viral hepatitis were not receiving anti-viral therapy at the time of the study. All alcoholic patients had abstained from alcohol for more than six months before enrollment. Because changes of cirrhotic cardiomyopathy are clinically subtle and unrelated to the presence of organic diseases, a negative cardiac and pulmonary history, a normal examination by a cardiologist, and normal electrocardiograph, chest $\mathrm{x}$-ray, spirometry and oximetry tests were mandatory for inclusion in the study.

\section{HRQoL}

The 36-item Short Form health survey (SF-36) was used to assess HRQoL. The reliability and validity of this measure are well- established and normative data are available for various populations $(10,11)$. The SF-36 has been used in patients with chronic liver disease (12). More specific disease-targeted measures of HRQoL for patients with chronic liver disease have also been developed $(13,14)$ but have not yet been widely used. Eight subscales were computed using standard procedures (10); higher scores indicate better functioning. The eight subscales of the SF-36 can be combined to create physical and mental health composite scores that are statistically uncorrelated $(15,16)$. These scores were problematic for the present study because the vitality subscale is included in both the physical and mental health composite scores, which would confound relations with the fatigue measures. Also, the validity of creating mental and physical health components scores that are statistically uncorrelated is questionable, given that mental and physical health are interrelated $(17,18)$. In the present study, physical and mental health scores were created using procedures comparable with those used in creating the composite scores $(15,16)$ with the exceptions noted above (ie, vitality excluded), allowing mental and physical scores to be correlated. The specific steps were as follows: raw subscale scores were converted to Z-scores using population norms; physical and mental health scores were created using the three subscales that are conceptually and empirically most strongly related to each domain of health; and scores transformed to T-scores to aid interpretation. The physical health score was the average of the physical functioning, physical role functioning and bodily pain subscales. Higher scores indicate few limitations due to health in performing physical work or daily activities, and little pain/few limitations due to pain. The mental health score was the average of the mental health, emotional role functioning and social functioning subscales. Higher scores indicate few limitations in work or daily activities due to emotional problems, feeling peaceful, happy and calm, and able to perform normal social activities without interference due to physical and emotional problems. The physical functioning subscale was used alone as a measure of limitations in physical activities due to health. Previously published results from normal individuals aged 55 to 64 years $(10,11)$ were used as comparisons for results of patients in the present study.

\section{Fatigue}

Two measures were used to assess the feelings of fatigue and impact of fatigue. Patients rated their fatigue during the previous two weeks using the Fatigue Assessment Inventory (FAI). The reliability and validity of the FAI has been established (19). The Fatigue Severity Score (FSS) of the FAI was used as a measure of overall limitations due to fatigue. This subscale includes items that relate mainly to the degree to which fatigue interferes with activities (eg, "fatigue interferes with my physical functioning"). The mean fatigue severity score in a small sample of healthy controls was $2.53(\mathrm{SD}=1.18)(19)$. In a study of primary biliary cirrhosis patients (3), means for fatigued patients and nonfatigued patients were $4.56(\mathrm{SD}=1.6)$ and $2.4(\mathrm{SD}=1.2)$, respectively. The vigor subscale of the SF-36 was used to examine feelings of fatigue.

\section{Depression}

Depressive symptomatology was measured using the Centre for Epidemiology-Depression Scale (CES-D). This measure is widely used in both healthy and medical populations and has established reliability and validity (20). Cut-offs of 16 and 27, respectively, were used to indicate patients with mildly (20) and severely 
$(21,22)$ elevated levels of depressive symptoms. Radloff (20) reported means of 7.94, 8.17 and 9.25 in three community-based samples, respectively. Cauch-Dudek et al (5) reported means of 11.5 for fatigued primary biliary cirrhosis patients and 5.12 for nonfatigued patients.

\section{Cardiac assessment}

Cirrhotic cardiomyopathy is a subtle condition only detected by echocardiograph or cardiopulmonary studies. The study design of the cardiopulmonary assessment of the study has been detailed in a previous paper and shall not be repeated here (8). Briefly, all medications that could potentially affect cardiac function or volume status such as beta-blockers or diuretics were withheld for a week before the study. Cirrhotic cardiomyopathy is characterized by the presence of myocardial thickening and diastolic dysfunction with or without diminution of left ventricular dimension $(23,24)$. While baseline systolic function is preserved, there is inability to augment cardiac output to physiological or pharmacological stress (25-27) with a reduction in exercise capacity and abnormal oxygen consumption. Therefore, all study subjects underwent a two-dimensional echocardiograph to assess cardiac structure (interventricular septal thickness, left ventricular relative wall thickness) and diastolic function (E/A ratio [contribution of ventricular filling by atrial systole, lower ratios being reflective of diastolic dysfunction], isovolumic relaxation time, deceleration time); a radionuclide angiography (RNA) to assess noninvasively cardiac chamber volumes and ejection fraction (EF) (28); and an upright cycle ergometry with repeat RNA measurements to assess the cardiac response to exercise. For this, the patient pedaled against a continuously increasing exercise load after a $1 \mathrm{~min}$ warm-up. Increasing increments of work were applied until symptom-limited exhaustion. Breath-by-breath measurements of expired gases provided data for the determination of oxygen consumption at maximal exertion $\left(\mathrm{VO}_{2} \max \right)$ and the ventilatory anaerobic threshold (the point at which lactic acid is produced by the body) using the gas exchange threshold (V slope method) (29).

\section{Statistics}

Single population $t$ test statistics were used to test differences between our sample and norms on standardized questionnaires. Independent sample $t$ tests were used to analyze differences between preascitics and ascitics. Pearson correlations were used to examine relations among variables. $\mathrm{P}<0.05$ was regarded as statistically significant.

\section{RESULTS}

\section{Demographics}

Baseline characteristics of the study patients are outlined in Table 1. The mean age of the patients was $54.4 \pm 3.1$ years. Preascitic cirrhotic patients had a Child-Pugh score of $5.6 \pm 0.3$ versus $9.1 \pm 0.5$ in the ascitic patients $(\mathrm{P}<0.05)$. Patients were well matched for body surface area (preascitics $1.94 \pm 0.05 \mathrm{~m}^{2}$ versus ascitics $1.92 \pm 0.04 \mathrm{~m}^{2}$ ) and BMI (preascitics $26.5 \pm 1.0 \mathrm{~kg} / \mathrm{m}^{2}$ versus ascitics $26.1 \pm 0.9 \mathrm{~kg} / \mathrm{m}^{2}$ ), and, therefore, patients were neither overweight nor emaciated.

\section{HRQoL}

Figure 1 presents comparisons between means on all eight subscales of the SF-36 for patients in the present study compared with norms from 55- to 64-year-olds $(10,11)$. Differences between cirrhotic patients and controls were most pronounced
TABLE 1

Baseline characteristics of study participants

\begin{tabular}{lcccc}
\hline & $\begin{array}{c}\text { All patients } \\
(\mathbf{n = 3 0})\end{array}$ & $\begin{array}{c}\text { Preascitics } \\
(\mathbf{n}=14)\end{array}$ & $\begin{array}{c}\text { Ascitics } \\
(\mathbf{n}=16)\end{array}$ & $\begin{array}{c}\text { Group } \\
\text { comparisons }\end{array}$ \\
\hline Age & $54.4 \pm 3.1$ & $51.6 \pm 2.3$ & $56.8 \pm 2.4$ & $\mathrm{t}(28)=1.66$ \\
Sex (M/F) & $28 / 2$ & $14 / 0$ & $14 / 2$ & \\
Etiology & $18 / 12$ & $6 / 8$ & $12 / 4$ & \\
$\quad(\mathrm{EtOH} / \mathrm{non}-\mathrm{EtOH})$ & & & & \\
Child-Pugh & $7.5 \pm 1.6$ & $5.6 \pm 0.3$ & $9.1 \pm 0.5$ & $\mathrm{t}(28)=5.63^{*}$ \\
$\mathrm{BSA}\left(\mathrm{m}^{2}\right)$ & $1.93 \pm 0.05$ & $1.94 \pm 0.05$ & $1.92 \pm 0.04$ & \\
$\mathrm{BMI}\left(\mathrm{kg} / \mathrm{m}^{2}\right)$ & $26.3 \pm 0.9$ & $26.5 \pm 1.0$ & $26.1 \pm 0.9$ & \\
$\mathrm{Hgb}(\mathrm{g} / \mathrm{dL})$ & $125.5 \pm 4.5$ & $137.3 \pm 3.3$ & $115.1 \pm 5.3$ & \\
$\quad$ Normal (M 140-180; F 130-170) & & &
\end{tabular}

${ }^{*} P<0.001$ ascitics versus preascitics. Data is presented as \pm SEM. BMI Body mass index; BSA Body surface area; EtOH Alcohol; F Female; Hgb Hemoglobin; M Male; $t$ Student's t test

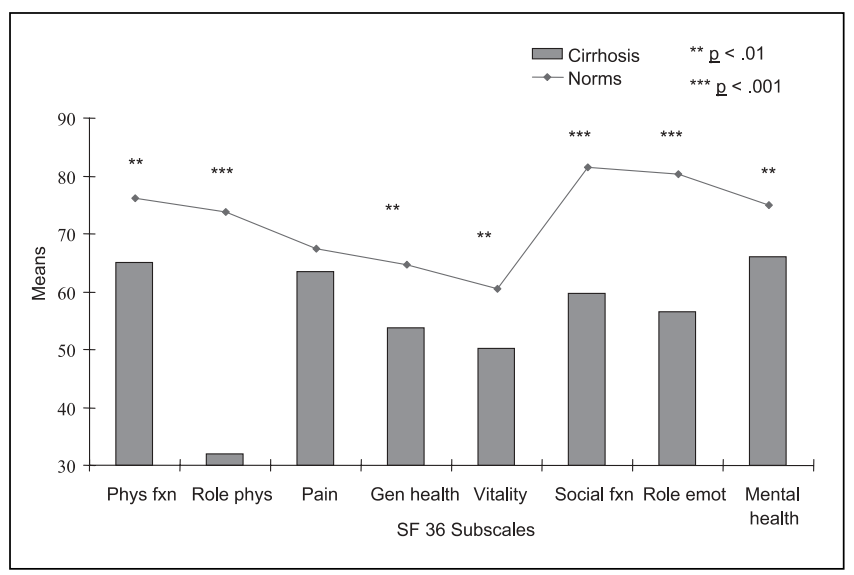

Figure 1) Comparison between cirrhotic patients and norms for healthy 55- to 64-year-olds on the Short Form-36 quality of life measure. $* * P<0.01, * * * P<0.001$ cirrhotics versus norms

in scales that assessed the effect of their disease on ability to perform expected physical roles (32 versus 73, $\mathrm{P}<0.001$ ), ability to perform expected emotional and social roles (56 versus 79, $\mathrm{P}<0.001$ ), as well as overall social functioning (60 versus 80 , $\mathrm{P}<0.01$ ). Physical function (65 versus $76, \mathrm{P}<0.01)$, mental health (66 versus $73, \mathrm{P}<0.01)$ and general health $(54$ versus 64 , $\mathrm{P}<0.01)$ scores were also lower in cirrhotic patients compared with controls. Cirrhotic patients also reported decreased vitality (49 versus $59, \mathrm{P}<0.01$ ), a scale traditionally used to assess fatigue (30), compared with norms. Patients with better physical HRQoL also had better mental HRQoL ( $r=0.66, \mathrm{P}<0.001)$. Given the sex distribution of our patient population, analyses were repeated comparing the male patients with norms for males only. The same differences in the various subscales were also observed (data not shown).

\section{Fatigue}

Patients' level of fatigue, based on the FSS from the FAI, was significantly higher (4.46) when compared with controls (2.53) $(\mathrm{P}<0.001)$. This finding compares with patients with primary biliary cirrhosis who were fatigued and had an FSS score of 4.56 (3) Likewise, scores on the vitality subscale of the SF-36 were significantly lower (ie, greater fatigue) compared 


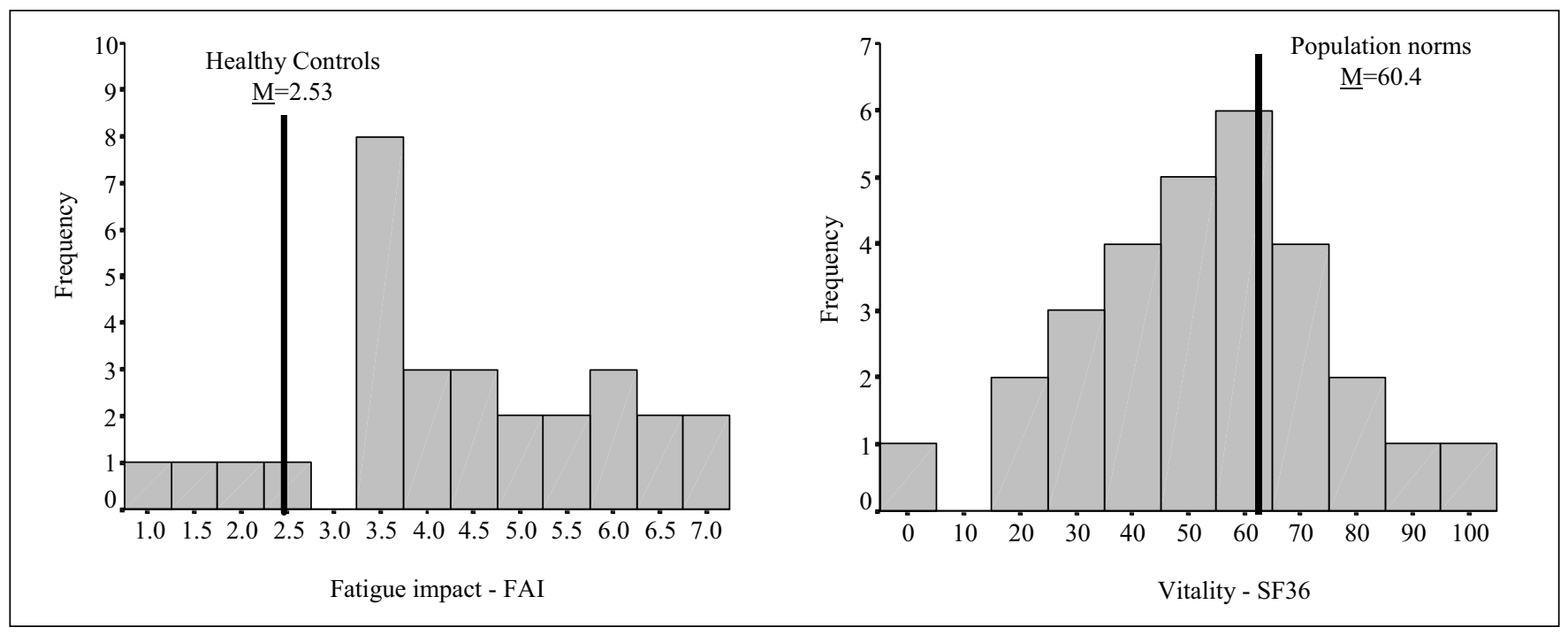

Figure 2) Impact for fatigue and vitality of cirrhotic patients. FAI Fatigue assessment instrument; SF36 Thirty-six item short form health survey

with the scores for age-matched healthy controls. Levels of fatigue, however, were variable in this patient population (see Figure 2). Fatigue was less for alcohol-related cirrhotic patients (3.9) than nonalcoholic cirrhotic patients (5.3; Student's $t$ test $[\mathrm{t}]=2.5, \mathrm{P}<0.05)$. Feelings of fatigue (less vitality) were also less for alcohol-related cirrhotic patients (39.5) than non-alcoholic cirrhotic patients $(57.8 ; \mathrm{t}=2.4, \mathrm{P}<0.05)$. Fatigue severity was greater for hepatitis C-related cirrhotic patients (5.5) than nonhepatitis C-related cirrhotic patients $(4.0 ; \mathrm{t}=2.4, \mathrm{P}<0.05)$. Feelings of fatigue (less vitality) were also greater for hepatitis C-related cirrhotic patients (32.5) than nonhepatitis C-related patients $(57.9 ; \mathrm{t}=3.3, \mathrm{P}<0.01)$.

\section{Depression}

The mean depression score in cirrhotic patients, as measured by the CES-D, was $16.4 \pm 2.2$, much higher than reported community-based samples, suggesting mild depressive symptomatology (20).

\section{Assessment of cardiac structure and function}

Structural parameters: Table 2 shows that the interventricular septal thickness was significantly increased in cirrhotic patients compared with values for normal controls $(10.5 \pm 0.3 \mathrm{~mm}$ versus $8.7 \pm 0.3 \mathrm{~mm}, \mathrm{P}<0.05)$. The left ventricular relative wall thickness (left ventricular wall thickness plus septal thickness relative to the internal dimensions) was also significantly greater in the cirrhotic patients when compared with the values for controls $(0.43 \pm 0.02$ versus $0.37 \pm 0.01, \mathrm{P}<0.05)$.

Diastolic function: Diastolic function, as measured by the E/A ratio, was significantly lower in cirrhotics than norms for healthy controls $(1.17 \pm 0.05$ versus $1.38 \pm 0.15, \mathrm{P}<0.05)$, whereas isovolumic relaxation time was significantly increased in the cirrhotic patients as a group $(87.6 \pm 2.2 \mathrm{msec})$ versus the norms for healthy controls $(78.9 \pm 4.8 \mathrm{msec})$ $(\mathrm{P}<0.05)$ (Table 2).

Systolic function: Resting EF was significantly higher in cirrhotic patients $(64.1 \pm 3.3 \%)$ compared with norms for healthy controls $(58.9 \pm 1.6 \%, \mathrm{P}<0.05)$. However, resting cardiac index was similar in the patients compared with norms for healthy controls (Table 2). With exercise, cirrhotic patients were unable to adequately augment contractility (fractional increase in $\mathrm{EF} 4.4 \pm 2.5 \%$ versus $11.5 \pm 3.1 \%, \mathrm{P}<0.05)$ or cardiac output $(219 \pm 10 \%$ versus $345 \pm 53 \%, \mathrm{P}<0.05)$ compared with norms for healthy controls (Table 2).

Metabolic parameters: With symptom-limited exercise, cirrhotic patients exercised for shorter periods and achieved less peak oxygen consumption and workload compared with normal healthy individuals (Table 2). Cirrhotic patients' metabolic response to exercise, as measured by anaerobic threshold, was significantly reduced in cirrhotic patients compared with normal healthy controls $(10.5 \pm 0.7 \mathrm{~L} / \mathrm{min}$ versus $16.1 \pm 1.5 \mathrm{~L} / \mathrm{min}$, $\mathrm{P}<0.05)$.

\section{Relationship between HRQoL and disease severity}

No significant correlations were found between the physical health scores, mental health scores or the physical functioning subscales of SF-36 and severity of liver disease, as assessed by Child-Pugh score, presence of ascites, serum bilirubin, albumin or international normalized ratio.

\section{Relationship of cirrhotic cardiomyopathy and HRQoL and fatigue}

Parameters of cardiac structure and diastolic and systolic function were not significantly correlated with any of the subscales of the SF-36, including vitality or impact of fatigue as measured by the FSS. However, the metabolic effects of cirrhotic cardiomyopathy correlated with poor physical functioning. For example, low SF-36 physical functioning scores correlated with reduced anaerobic threshold $(\mathrm{r}=0.42, \mathrm{P}<0.05)$ and $\mathrm{VO}_{2} \max (\mathrm{r}=0.56, \mathrm{P}<0.001)$, and markers of reduced patient exercise capacity. Overall physical health also correlated with oxygen consumption $(\mathrm{r}=0.51, \mathrm{P}<0.01)$.

\section{Relationship of depression to HRQoL and fatigue}

Less vitality and greater impact of fatigue were significantly related to more depressive symptoms $(\mathrm{r}=0.55, \mathrm{P}<0.001$ and $\mathrm{r}=0.49, \mathrm{P}<0.05$, respectively) and poorer mental health-related 
overall quality of life. Greater vitality $(\mathrm{r}=0.48, \mathrm{P}<0.01)$, but not impact of fatigue $(\mathrm{r}=-0.16)$, was significantly related to better physical HRQoL. Fatigue was not related to physical functioning on the SF-36 or to liver disease severity (ascites, Child-Pugh score). To facilitate comparisons with other studies, SF-36 scores for patients in Child-Pugh class A $(n=12)$ were compared with those from patients in classes $\mathrm{B}$ or $\mathrm{C}$ $(\mathrm{n}=18)$. Patients in Child-Pugh classes B and C had significantly poorer physical HRQoL (Mean $[\mathrm{M}]=36.6, \mathrm{SD}=7.3$; $\mathrm{t}[28]=2.8, \quad \mathrm{P}<0.01)$ and physical functioning $(\mathrm{M}=56.8$; $\mathrm{SD}=22.8 ; \mathrm{t}[28]=2.8, \mathrm{P}<0.01)$ compared with patients in ChildPugh class A $(\mathrm{M}=45.7, \mathrm{SD}=10.4$ and $\mathrm{M}=79.2, \mathrm{SD}=20.9$, respectively). Patients in Child-Pugh class A had higher mental HRQoL scores $(M=46.1, S D=10.9)$ than classes $B$ and $C$ $(\mathrm{M}=39.4, \mathrm{SD}=8.3)$ although this difference was not statistically significant $(t[28]=1.9, P=0.07)$. There were no statistically significant differences between the classes in terms of fatigue or depression.

\section{DISCUSSION}

The main results of the present study are: patients with cirrhosis have diminished HRQoL and variable levels of fatigue; impairment in HRQoL and severity of fatigue are independent of the severity of liver disease; poor HRQoL or fatigue are not related to the presence of cirrhotic cardiomyopathy; and feelings and impact of fatigue were related to depressive symptoms and poorer mental HRQoL.

HRQoL was assessed using the SF-36 because of its multidimensionality, brevity, previous application in a variety of chronic diseases $(31,32)$ and the fact that it had been validated in patients with chronic liver disease (12). More specific disease-targeted measures of $\mathrm{HRQoL}$ for patients with chronic liver disease have been developed and validated $(13,14)$ but have not yet been widely used. Using the SF-36, we found a reduced HRQoL, which is independent of the severity of the liver disease. Vila and colleagues (33) also found no correlation between HRQoL and degree of hepatic insufficiency. Recently, Marchesini et al (34) suggested that, while patients with cirrhosis had diminished HRQoL compared with the normative Italian population, specific symptoms such as muscle cramps and pruritus may correlate better with impaired HRQoL than more traditional measures of disease severity (Child-Pugh score, ascites). Other studies, however, demonstrated that HRQoL in chronic liver disease, particularly the physical composite score, was a function of disease severity and the presence of ascites and portosystemic encephalopathy (14). Physical composite scores were better in patients with cholestatic liver disease than in patients with hepatocellular disease (35). Similar to Younossi et al (14), we found that patients in ChildPugh classes $\mathrm{B}$ and $\mathrm{C}$ had significantly poorer physical HRQoL that patients in Child-Pugh class A, although we found no correlation between Child-Pugh scores and HRQoL. This indicates that there are qualitative differences in physical HRQoL with advanced stages of liver disease. Patients in Child-Pugh classes B and C had poorer mental HRQoL than patients in class A. Although this was not statistically significant, the direction of this effect is what would be expected but is the opposite from that of Younossi et al $(14,35)$ who found better mental HRQoL with more advanced disease. Younossi et al $(14,35)$ developed composite mental HRQoL scores that force mental and physical scores to be uncorrelated. This scoring method in essence subtracts patients' physical health from
TABLE 2

Cardiac assessment variables and comparisons of cirrhotic patients and controls

\begin{tabular}{|c|c|c|c|}
\hline & $\begin{array}{c}\text { Control } \\
\text { Mean } \pm \text { SE }\end{array}$ & $\begin{array}{l}\text { Cirrhotic } \\
\text { Mean } \pm \text { SE }\end{array}$ & $t$ test \\
\hline \multicolumn{4}{|l|}{ Diastolic function parameters } \\
\hline $\mathrm{E} / \mathrm{A}$ & $1.38 \pm 0.15$ & $1.17( \pm 0.05)$ & $t(28)=4.42^{* *}$ \\
\hline Deceleration time (msec) & $217 \pm 14$ & $215( \pm 12)$ & $t(26)=0.20$ \\
\hline $\begin{array}{l}\text { Isovolumic relaxation time } \\
\text { (msec) }\end{array}$ & $78.9 \pm 4.8$ & $87.6( \pm 2.2)$ & $t(27)=3.85^{* *}$ \\
\hline \multicolumn{4}{|l|}{ Systolic function parameters } \\
\hline Ejection fraction (\%) & $58.9 \pm 1.6$ & $64.1 \pm 3.3$ & $t(28)=1.30$ \\
\hline $\begin{array}{l}\text { Cardiac index (at rest) } \\
\left(\mathrm{L} / \mathrm{min} / \mathrm{m}^{2}\right)\end{array}$ & $2.13 \pm 0.22$ & $2.13 \pm 0.17$ & $t(27)=0.01$ \\
\hline $\begin{array}{l}\text { Fractional change in ejection } \\
\text { fraction with exercise }(\%)\end{array}$ & $11.5 \pm 3.1$ & $4.4 \pm 2.5$ & $t(28)=1.41$ \\
\hline $\begin{array}{c}\text { Fractional increase in cardiac } \\
\text { output with exercise (\%) }\end{array}$ & $345 \pm 53$ & $219 \pm 10$ & $t(27)=3.70^{* *}$ \\
\hline \multicolumn{4}{|l|}{ Metabolic parameters } \\
\hline Anaerobic threshold $(\mathrm{L} / \mathrm{min})$ & $16.1 \pm 1.5$ & $10.5 \pm 0.7$ & $t(29)=3.64^{* *}$ \\
\hline $\mathrm{VO}_{2} \max (\mathrm{L} / \mathrm{min})$ & $2.18 \pm 0.23$ & $1.49 \pm 0.12$ & $t(30)=2.71^{*}$ \\
\hline Work (kilopon meter) & $929 \pm 91$ & $653 \pm 42$ & $t(30)=3.40^{* *}$ \\
\hline \multicolumn{4}{|l|}{ Structural parameters } \\
\hline $\begin{array}{l}\text { Interventricular septal } \\
\text { thickness }(\mathrm{mm})\end{array}$ & $8.7 \pm 0.3$ & $10.5 \pm 0.3$ & $t(26)=5.69^{* *}$ \\
\hline $\begin{array}{l}\text { Left ventricular relative } \\
\text { wall thickness }\end{array}$ & $0.37 \pm 0.01$ & $0.43 \pm 0.02$ & $\mathrm{t}(24)=4.01^{\text {** }}$ \\
\hline
\end{tabular}

${ }^{*} P<0.01 ;{ }^{* *} P<0.001$ cirrhotics versus norms. $V_{2}$ max Oxygen consumption at maximal exertion

their mental health when computing total scores. Our method of scoring the SF-36 allowed patients mental and physical HRQoL to be correlated and thus yields a more accurate reflection of the relation between physical and mental health. Namely, with advanced disease states and worse physical health, patients tend to experience decreased mental HRQoL.

As in the present study, Vila et al (33) used the generic SF-36 instrument to investigate HRQoL in cirrhotic patients, whereas Younossi et al $(14,35)$ used the newly developed Chronic Liver Disease Questionnaire (CLDQ). One could hypothesize, that while the generic SF-36 and the CDLQ can both measure impaired HRQoL in cirrhotic patients, only the CLDQ is sensitive enough to document a correlation between disease-specific subscales and severity of liver disease. Alternatively, in the Younossi study (35), 29\% of patients had no evidence of cirrhosis, increasing the spectrum of disease severity and perhaps allowing correlations to be made between HRQoL and stage of liver disease.

We demonstrated that patients with chronic liver disease reported a greater impact of fatigue than what is normal for healthy controls. Impact of fatigue and feelings of fatigue were related to the etiology but not the severity of liver disease. Similarly, Younossi et al (35) found no correlation of the SF-36 vitality scale with disease severity. Fatigue has been examined extensively in patients with chronic hepatitis $\mathrm{C}(3,4,36)$. The fact that successful treatment of the hepatitis does not consistently alter the subjective complaint of fatigue has led some to speculate that fatigue may be related to coexistent depression, psychosocial issues or disease labelling. We found that, in cirrhotic patients, both feelings and impact of fatigue were significantly related to depressive symptoms and impaired mental 
HRQoL. These relations are likely bi-directional. The more fatigued patients are, the more likely they are to be depressed due to their physical limitations, and if patients are depressed, they are more likely to feel fatigued.

We confirmed that cirrhotic cardiomyopathy exists and that functional and structural parameters of this cardiomyopathy correlated with disease, as assessed by Child-Pugh score, as well as the presence of ascites. In addition, the major sequelae of impaired cardiac function, namely, reduced oxygen consumption, anaerobic threshold and poor work performance, were also related to degree of liver dysfunction. The lack of a correlation between specific parameters of cirrhotic cardiomyopathy and diminished HRQoL and fatigue is interesting. However, similar studies of patients with congestive heart failure have generally failed to consistently correlate impairment in quality of life with parameters of systolic dysfunction, specifically EF (37-39). Severity of congestive cardiomyopathy, however, correlated with diminished survival. Furthermore, interventions, such as angiotensin-converting enzyme inhibition, which improved both survival and objective indices of cardiomyopathy in this setting, failed to have a consistent effect on HRQoL. Therefore, using this as an analogy, it is perhaps not surprising that diminished HRQoL and fatigue were not specifically related to parameters of cardiac dysfunction in cirrhosis. However, metabolic response to exercise as measured by the anaerobic threshold correlated with the physical functioning scale of the SF-36 scale and maximal oxygen consumption correlated with overall physical quality of life and physical functioning. HRQoL and physical functioning may be, in part, a function of overall metabolic efficiency and utilization of oxygen, related to both delivery of oxygen at tissue level (cardiac output, left ventricular function), which is affected by the

\section{REFERENCES}

1. La Vecchia C, Levi F, Lucchina F, Franceschi S, Negri E. Worldwide patterns and trends in mortality from liver cirrhosis, 1953 to 1990. Ann Epidemiol 1994;4:480-6.

2. Jain A, Reyes J, Kashyap R, et al. Long-term survival after liver transplantation in 4,000 consecutive patients at a single center. Ann Surg 2000;232:490-500.

3. Nelles S, Abbey S, Stewart DE, et al. Fatigue assessment in patients with Hepatitis C. Gastroenterology 1996;110:1276A.

4. Goh J, Coughlan B, Quinn J, O'Keane JC, Crowe J. Fatigue does not correlate with the degree of hepatitis or the presence of autoimmune disorders in chronic hepatitis C infection. Eur J Gastroenterol Hepatol 1999;11:833-8.

5. Cauch-Dudek K, Abbey S, Stewart DE, Heathcote EJ. Fatigue in primary biliary cirrhosis. Gut 1998;43:705-10.

6. Prince M, Ashley D, Edwards N, et al. Fatigue significantly impairs the quality of life of patients with primary biliary cirrhosis. Hepatology 1999;30:564A.

7. Wong F, Liu P, Lilly L, Bomzon A, Blendis L. Role of cardiac structural and functional abnormalities in the pathogenesis of hyperdynamic circulation and renal sodium retention in cirrhosis. Clin Sci 1999;97:259-67.

8. Wong FS, Girgrah N, Graba J, Allidina Y, Liu P, Blendis L. The effect of cirrhotic cardiomyopathy in cardiac response to exercise in cirrhosis. Gut 2001;49:268-75

9. Krontam V, Salem D, Ponleur H, et al. Baseline quality of life as a predictor of mortality and hospitalization in 5025 patients with congestive heart failure. SOLVD Investigations. Am J Cardiol 1996;78:890-5

10. Ware JE, Snow KK, Kosinski M, Grandek B. SF-36 health survey: Manual and interpretation guide, Boston MA, The Health Institute, New England Medical Centre; 1993.

11. Ware JE, Sherbourne CD. The MOS 36-item short-form health survey (SF-36). Med Care 1992;30:473-83.

12. Sanyal AJ, Gennings C, Reddy KR, et al. Validation of a new presence of cirrhotic cardiomyopathy, and the ability of the tissue to extract oxygen effectively. One might speculate that while the first component of this equation, namely left ventricular dysfunction or cardiomyopathy, may affect mortality and morbidity, the second component, affected by factors such as skeletal muscular vasculature and mass and efficiency of oxygen extraction at the tissue level that some have termed cirrhotic myopathy, might play a more important role in determining the patient's perception of well-being.

\section{CONCLUSIONS}

This study confirms our clinical experience that patients with cirrhosis have diminished HRQoL and experience greater fatigue. Importantly, we conclude that, while survival might be impacted by such factors as severity of liver disease and the presence of cirrhotic cardiomyopathy, HRQoL or patients' perception of health and impact of fatigue is not. We submit that the concomitant depressive symptomatology, though not necessarily causative, is a superior predictor of diminished HRQoL and the subjective experience of fatigue in cirrhotic patients. In future, greater attention should be placed on the importance of psychosocial and psychopharmacological intervention in improving HRQoL. We conclude that while fatigue and diminished HRQoL are present in patients with chronic liver disease, cirrhotic cardiomyopathy does not appear to be the cause.

ACKNOWLEDGEMENTS: The authors would like to thank Yasmin Alidina for performing the cardiopulmonary studies on all cirrhotic patients. Nigel Girgrah was a recipient of a Fellowship in Gastroenterology provided by the Canadian Association of Gastroenterology and Janssen Ortho Inc. quality-of-life instrument for patients with liver disease. Hepatology 1997;26:355A. (Abst)

13. Gralnek IM, Hays RD, Kilbourne A, et al. Development and evaluation of the Liver Disease Quality of Life Instrument in persons with advanced chronic liver disease: the LDQOL 1.0. Am J Gastroenterology 2000;95:3552-65.

14. Younossi ZM, Guyatt G, Kiwi M, Boparai N, King D. Development of a disease specific questionnaire to measure health related quality of life in patients with chronic liver disease. Gut 1999;45:295-300.

15. Ware JE, Kosinski M, Bayliss MS, McHorney CA, Rogers WH, Raczek A. Comparison of methods for the scoring and statistical analysis of SF-36 health profile and summary measures: Summary of results from the Medical Outcomes Study. Med Care 1995;33:AS264-79.

16. Ware JE, Snow KK, Kosinksi M, Gandek B. SF-36 Physical and Mental Health Summary Scales: A User's Manual. Boston, Massachussets: The Health Institute, New England Medical Center, 1994.

17. Simon GE, Revicki DA, Grothaus L, VonKorff M. SF-36 summary scores: Are physical and mental health truly distinct? Med Care 1998;36:567-72.

18. Hays RD, Marshall GN, Wang EY, Sherbourne CD. Four-year crosslagged associations between physical and mental health in the Medical Outcomes Study. J Consult Clin Psychol 1994;62:441-9.

19. Schwartz JE, Jandorf L, Krupp LB. The measurement of fatigue: A new instrument. J Psychosom Res 1993;37:753-62.

20. Radloff LS. The CES-D scale. A self-report depression scale for research in the general population. Appl Psychol Measure 1977;1:385-401.

21. Zich JM, Attkisson CC, Greenfield TK. Screening for depression in primary care clinics: The CES-D and the BDI. Int J Psych Med 1990;20:259-77.

22. Santor DA, Zuroff DC, Ramsay JO, Cervantes P, Palacios J. Examining scale discriminability in the BDI and CES-D as a function of depressive severity. Psychol Assess 1995;7:131-9. 
23. Pozzi M, Carugo S, Boari G, et al. Functional and structural cardiac abnormalities in cirrhotic patients with and without ascites. Hepatology 1997;26:1131-7.

24. Finucci G, Desiseri A, Sacerdoti D, et al. Left ventricular diastolic dysfunction in liver cirrhosis. Scan J Gastroenterol 1996;31:279-84.

25. Bernardi M, Rubboli A, Trevisani F, et al. Reduced cardiovascular responsiveness to exercise-induced sympathoadrenergic stimulation in patients with cirrhosis. J Hepatology 1991;12:207-16.

26. Laffi G, Barletta G, La Villa G, et al. Altered cardiovascular responsiveness to active tilting in nonalcoholic cirrhosis. Gastroenterology 1997;113:891-8.

27. Grose RD, Nolan J, Dillon JF, et al. Exercise-induced left ventricular dysfunction in alcoholic and non-alcoholic cirrhosis. J Hepatol 1995;22:326-32.

28. Wong F, Liu P, Tobe S, Morali G, Blendis LM. Central blood volume in cirrhosis: Measurement by radionuclide angiography. Hepatology 1994;19:312-21.

29. Wasserman K. Diagnosing cardiovascular and lung pathophysiology from exercise gas exchange. Chest 1997;112:1091-101.

30. Bonkovsky HL, Wooley JM. Reduction in health-related quality of life in chronic hepatitis $\mathrm{C}$ and improvement with interferon therapy. The Consensus Interferon Study Group. Hepatology 1999;29:264-70

31. Phillips RC, Lansky DJ. Outcomes management in heart valve replacement surgery: Early experience. J Heart Valve Dis 1992;1:42-50.

32. Kurtin PS, Davies AR, Meyer KB, DeGiacomo JM, Kantz ME. Patient-based health status measures in out-patient dialysis: Early experiences in developing an outcomes assessment program. Med Care 1992; 30:MS136-49.

33. Vila MC, Marquez J, Coll S, Andreu M, Bory F, Sola R. Health status evaluation in compensated cirrhotic patients. Relationship with hepatic insufficiency. Hepatology 1997;26:620A.

34. Marchesini G, Bianchi G, Amodio P, et al. Factors associated with poor health-related quality of life of patients with cirrhosis. Gastroenterology 2001;120:170-8.

35. Younossi ZM, Boparai N, Kiwi ML, McCormick M, Guyatt G. Extensive evaluation of quality of life (QOL) in a large cohort of patients with a variety of chronic liver diseases. Hepatology 1998;28:306A.

36. Kleinman LS, Zodet M, Revicki D. Evaluation of the scaling and psychometric properties of the fatigue severity scale for use in patients with chronic hepatitis. Hepatology 1999;30:616A.

37. Wenger NK. Quality of life: Can and should it be assessed in patients with heart failure? Cardiology 1989;76:391-8.

38. Dracup K, Walden JA, Stevenson LW, Brecht ML. Quality of life in patients with advanced heart failure. J Heart Lung Transplant 1992;11:273-79.

39. Catagna D, Ponte E, Burri R. The concept of quality of life in cardiac failure. Minerva Med 1997;88:151-62. 


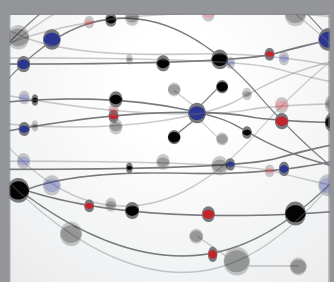

The Scientific World Journal
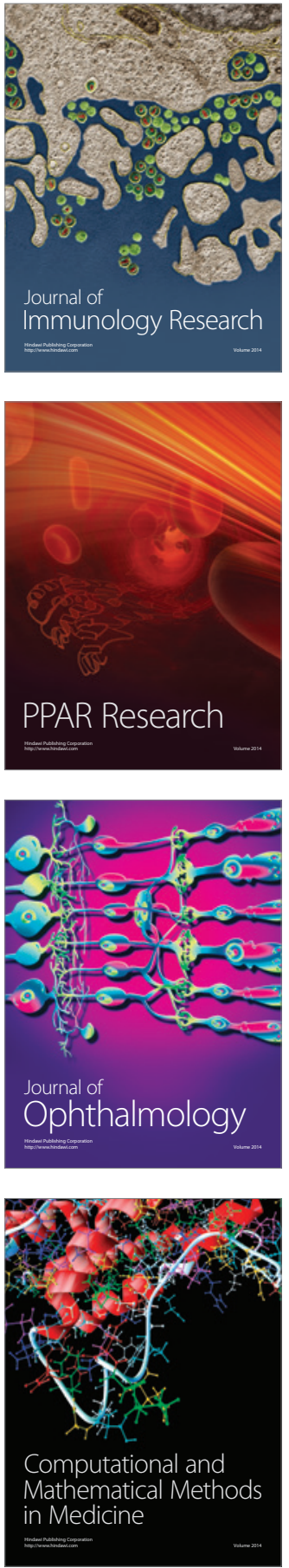

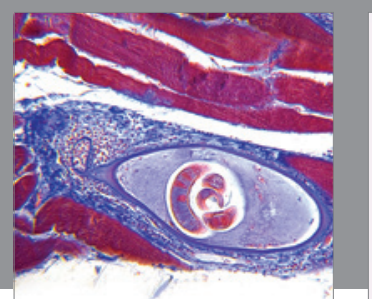

Gastroenterology Research and Practice

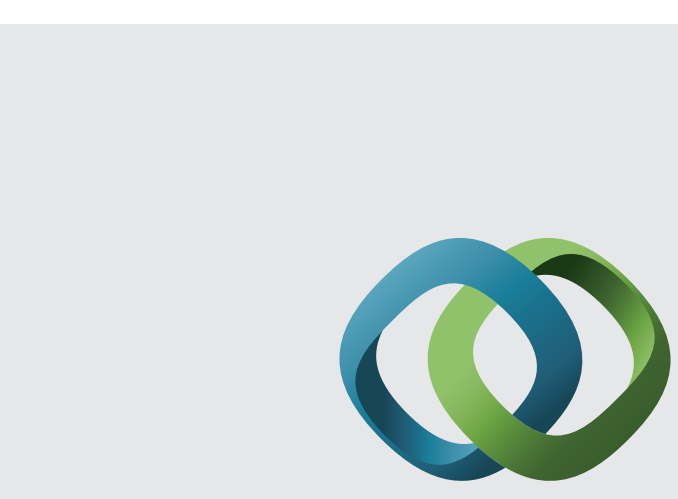

\section{Hindawi}

Submit your manuscripts at

http://www.hindawi.com
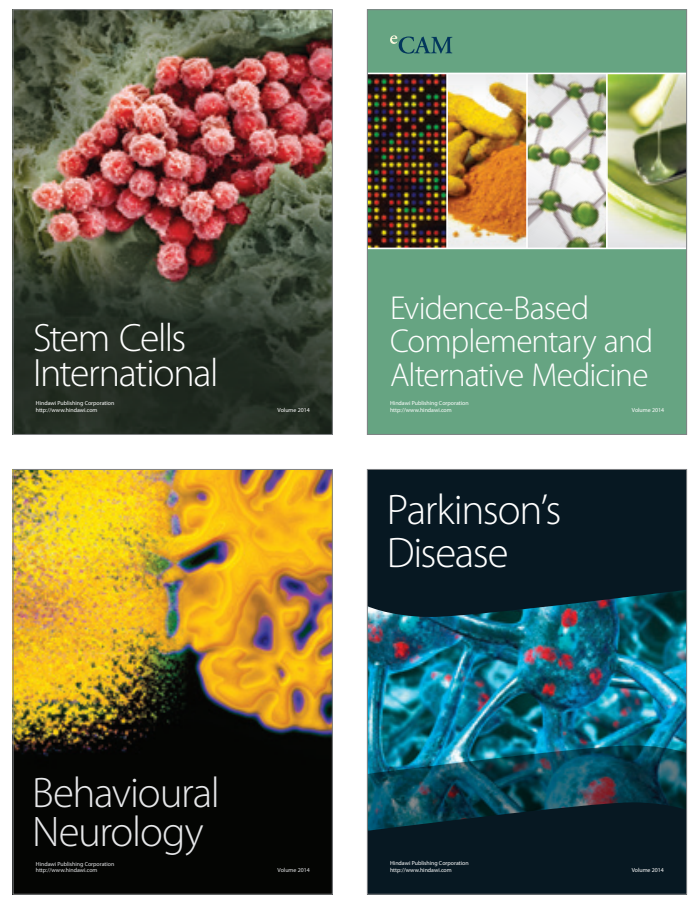
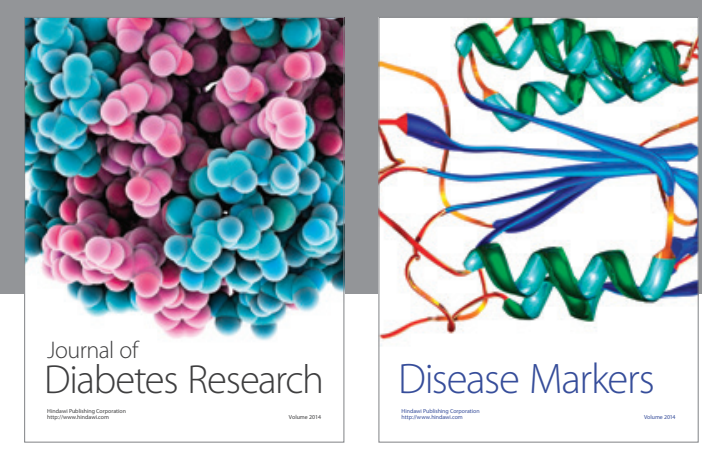

Disease Markers
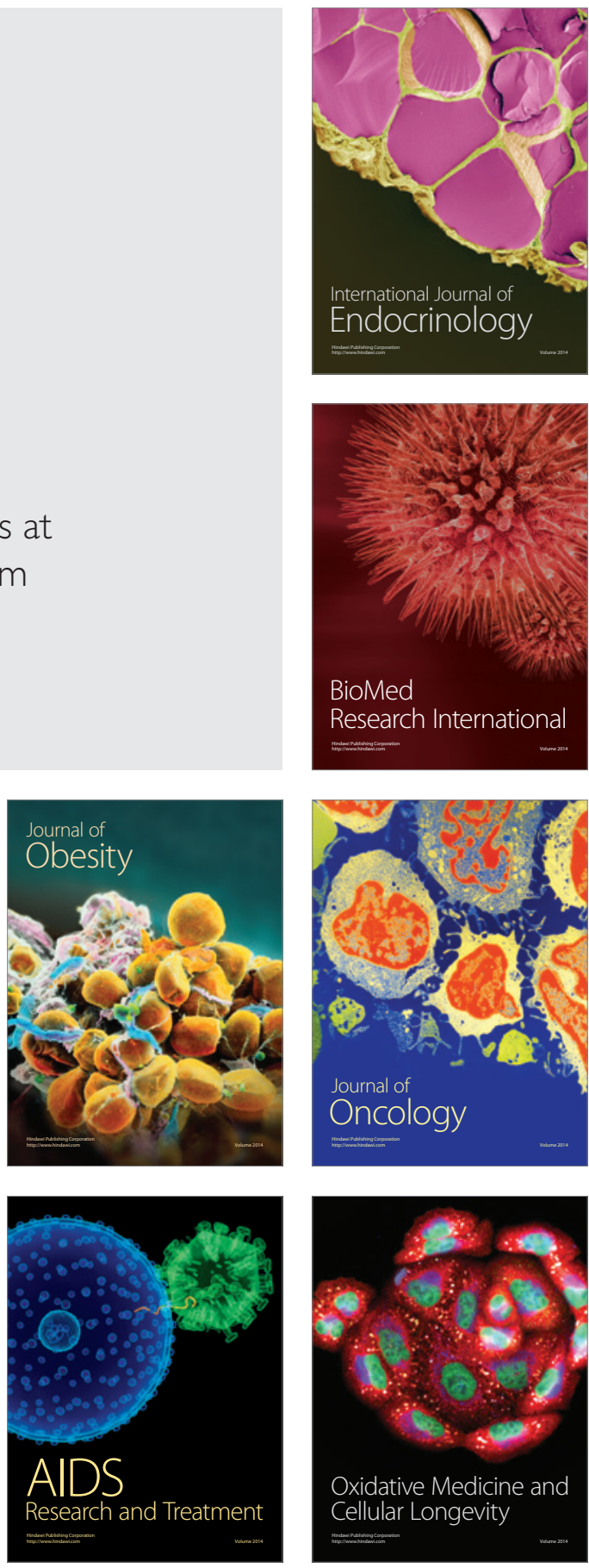